SHORT COMMUNICATION

\title{
Comparative Studies on Growth and Haemato-biochemical Parameters of Kadaknath and Chabro Chickens Reared under Organic Condition
}

\author{
Sandip Kumar", S.K. Singh and B.S. Kirar \\ JNKVV, Krishi Vigyan Kendra, Tikamgarh (MP), INDIA \\ "Corresponding author: S Kumar; E-mail: getsandipkumar@rediffmail.com
}

Received: 27 Aug., 2021

Revised: 22 Sept., 2021

Accepted: 28 Sept., 2021

\begin{abstract}
A comparative study on physical growth and blood parameter was investigated between Kadaknath and Chabro chickens. A total of 100 day old chicks, 50 of Kadaknath and 50 of Chabro birds were used in the study. Chabro as coloured birds gained significantly higher $(\mathrm{P}<0.001)$ body weight comparison to Kadaknath as $861 \pm 4.36$ and $338 \pm 3.99$ respectively. The haemoglobin concentration was significantly $(\mathrm{P}<0.05)$ higher in Kadaknath $(12.36 \pm 0.09)$ than Chabro $(9.6 \pm 0.36)$. Cholesterol content in Chabro $(101.26 \pm 1.93)$ was significantly $(\mathrm{P}<0.001)$ higher than Kadaknath $(101.26 \pm 1.93)$. It was concluded that although weight gain was higher in Chabro birds but quality of meat of Kadaknath was much higher than Chabro and fetch higher price to farmers keeping scenario of market preferences.
\end{abstract}

\section{HIGHLIGHTS}

0 Study on Kadaknath and Chabro birds body weight and haemato-biochemical parameters.

0 Kadaknath is a geo tag bird of Madhya Pradesh.

Keywords: Body weight, Chicken, Haematological parameters, Biochemical parameters, Kadaknath and Chabro

Chickens are fast growing birds and supposed to be a good converter of feed. Chabro was developed by Central Poultry Breeding Farm, Chandigarh and Kadaknath is a native bird of Jhabua, Madhya Prdesh, India procured from Sate farm Bharari, Jhansi and Nanaji Deshmukh Pashu Chikitsa Vigyan Vishwa Vidhyalaya, Jabalpur respectively.

Azolla is an aquatic fern rich in protein and minerals, which can we offered as such basis or on dry basis. Poultry development in India has made good progress since last many decades evolving from backyard farming to a full-fledged commercial farming mainly due to intensive and comprehensive research and development initiated by the government and subsequently taken up by the stake holders. It has also been observed now a day that demands for rural backyard poultry farming is significantly high among the poor villagers. However, their growth potential is quite low. India is home to many indigenous breeds of chickens that have their own characteristics. Hematological and biological tests could be used for monitoring health or for following of sickness birds. Normal value for these parameters (Elagib et al., 2012) and genetically approved industrial species of birds (Dutta et al., 2013) were measured and a comprehensive database was prepared as their blood-profiles with this normal analysis of hematological parameters can be done for predicting potential resistance (Aikpitanyi and Egweh 2020), estimation of body weights (Singh et al., 1998), diagnosis of disease (Prameela Rani et al., 2011) and many other purposes. Such information may also be used to improve genetic potential of indigenous chickens (Alevi

How to cite this article: Kumar, S., Singh, S.K. and Kirar, B.S. (2021). Comparative Studies on Growth and Haemato-biochemical Parameters of Kadaknath and Chabro Chickens Reared under Organic Condition. J. Anim. Res., 11(05): 947-950.

Source of Support: None; Conflict of Interest: None क) 
et al., 2012). The normal physiological values under local conditions may also be used for proper management, feeding, breeding and prevention of diseases. Keeping all these things in view, present study is intended to evaluate the hematological and serobiochemical profiles of Kadaknath and Chabro in agro climatic area of Bundelkhand region fed on local available feed ingredients and azolla.

A total of 100 day old chicks, 50 of Kadaknath and 50 of Chhebro birds were used in the study. Birds were kept in the poultry shed which was an open sided house in the KVK Campus, College of Agriculture, Tikamgarh, Madhya Pradesh, India. Birds were fed starter ration up to 08 weeks and grower ration up to 20 weeks along with 100 gram of azolla/bird on fresh basis and water was provided ad-libitum. Light was provided 18 hours daily. Diets were formulated using maize, deoiled rice polish and soybean meal supplements. These ingredients were analyzed for proximate constitutes before formulation of diets. Feed intake was recorded weekly basis and body weight was recorded on fort night basis, blood samples ( $2 \mathrm{ml} / \mathrm{bird})$ were taken from the wing vein using syringe and were collected with and without EDTA (Ethylene Diamine Tetra acetic acid) for hematological and biochemical analysis.

The Experimental data were collected for statistical analysis; means were compared using Duncan's multiple range tests.

Comparison in the body weight between Kadaknath and Chabro is presented in Table 1.

Table 1: Average body weight from 0 to 10 weeks of age

\begin{tabular}{lll}
\hline Age of Weeks & Kadaknath & Chabro \\
\hline 0 & $27 \pm 0.18$ & $36 \pm 0.21$ \\
1 & $41 \pm 0.43$ & $81 \pm 0.29$ \\
2 & $62 \pm 0.79$ & $135 \pm 0.32$ \\
3 & $89 \pm 1.20$ & $205 \pm 1.49$ \\
4 & $126 \pm 2.00$ & $285 \pm 2.10$ \\
5 & $155 \pm 2.61$ & $390 \pm 2.58$ \\
6 & $188 \pm 2.91$ & $485 \pm 3.10$ \\
7 & $241 \pm 3.42$ & $579 \pm 3.59$ \\
8 & $265 \pm 3.62$ & $672 \pm 3.93$ \\
9 & $302 \pm 3.89$ & $765 \pm 4.21$ \\
10 & $338 \pm 3.99$ & $861 \pm 4.36$ \\
\hline
\end{tabular}

\section{Body weight}

There is significant difference in body weight. Chabro as coloured birds gained significantly higher $(\mathrm{P}<0.01)$ body weight comparison to Kadaknath. (Mishra, 1983) reported that during field trials Kadaknath body weights were found little lower than rearing at farm conditions.

The comparative haematobiochemical parameters between Kadaknath and Chabro are presented in Table 2.

Table 2: Comparative Haemato-Biochemical Parameters during $10^{\text {th }}$ weeks

\begin{tabular}{lll}
\hline Parameter & Kadaknath & Chabro \\
\hline WBC $\left(10^{9} / \mathrm{l}\right)$ & $17.10 \pm 0.16$ & $18.16 \pm 1.3$ \\
RBC $\left(10^{6} / \mathrm{l}\right)$ & $2.64 \pm 0.11$ & $2.12 \pm 0.1$ \\
HGB $(\mathrm{g} / \mathrm{dl})$ & $12.36 \pm 0.09$ & $9.6 \pm 0.36$ \\
PCV $(\%)$ & $22.63 \pm 0.61$ & $19.69 \pm 0.82$ \\
Total Protein $(\mathrm{g} / \mathrm{dl})$ & $4.21 \pm 0.08$ & $4.23 \pm 0.31$ \\
Blood Glucose $(\mathrm{mg} / \mathrm{dl})$ & $369 \pm 2.01$ & $252 \pm 3.62$ \\
Cholesterol $(\mathrm{mg} / \mathrm{dl})$ & $101.26 \pm 1.93$ & $\mathrm{C}$ \\
Creatinine $(\mathrm{mg} / \mathrm{dl})$ & $0.69 \pm 0.05$ & $1.11 \pm 0.02$ \\
Bilirubin $(\mathrm{mg} / \mathrm{dl})$ & $23.16 \pm 1.89$ & $25.02 \pm 0.03$ \\
\hline
\end{tabular}

\section{Total red blood cell count (TRBC)}

The experiment revealed a significant $(\mathrm{P}<0.05)$ difference between two birds. Total RBC count in Kadaknath observed higher value than Chabro which is in agreement with the report of (Pandian et al., 2012).

\section{White blood corpuscles (WBC)}

The difference in total white blood corpuscles in both the birds were insignificant.

\section{Haemoglobin}

The haemoglobin concentration was significantly $(\mathrm{P}<$ 0.05) higher in Kadaknath than Chabro. Haemoglobin concentration was higher in vanraja (Panigraphy et al., 2017). However (Tyagi et al., 2007) observed haemoglobin concentration in broiler at $8^{\text {th }}$ weeks was $7.70 \mathrm{~g}$.

\section{Packed cell volume (PCV)}

There is significant $(\mathrm{P}<0.05)$ difference in $\mathrm{PCV}$ values 
Kadaknath birds have higher PCV value than Chabro. These findings were in agreement with the observations of (Addass et al., 2012; Guttani et al., 2016). The differences in PVC value status are many and it is difficult to discuss why the PCV values were changed among birds. The variables are age, season, physiological and nutritional condition etc.

\section{Total protein}

Total protein concentrations in both were almost similar. There were no significant differences in total protein value. The report was supported by (Mohanty et al., 2020).

\section{Blood glucose}

Blood glucose level was significantly $(\mathrm{P}<0.05)$ high in Kadaknath in comparison to Chabro. However, feed intake was less in Kadaknath. This may be due to fasting time or other factor like stress like heat which resulted in to increase blood glucose level (Khan et al., 2002).

\section{Cholesterol}

Cholesterol content in Chabro was significantly $(\mathrm{P}<0.001)$ higher than Kadaknath. The body activity of Kadaknath was higher other factor may be due to heat stress, which reduces the concentration of cholesterol. These findings were supported by (Shanmathy et al., 2020).

\section{Creatinine}

Creatinine value recorded significantly $(\mathrm{P}<0.05)$ higher in Chabro chicken which showed higher muscle metabolism. Similarly, (Polat et al., 2011) reported that creatinine levels varied in broilers due to diet.

\section{Bilirubin}

There was no significant difference in serum bilirubin concentration in both Kadaknath and Chabro chicken. Similar findings reported by (Bora et al., 2017) in Kadaknath and Rajasri chicken.

\section{CONCLUSION}

It may be concluded that although weight gain was higher in Chabro birds but quality of meat of Kadaknath was much higher than Chabro and fetch higher price to farmers keeping scenario of market preferences as well as religious concern.

\section{ACKNOWLEDGEMENTS}

Authors are thankful to the ATARI, zone IX, ICAR for conducting research under revolving fund of the centre.

\section{REFERENCES}

Addass, P.A., David, D.L., Edward, A., Zira and Midau, K.E. 2012. A effect of age, sex and management system on some hematological parameters of intensively and semi-intensively kept chicken in Mubi, Adamawa state, Nigeria. Iranian J. Appl. Anim. Sci., 2(3): 277-282.

Aikpitanyi, K.U. and Agweh, N.O. 2020. Hematological and biochemical profile of broiler chickens fed diets containing ginger and black pepper additives. Nigerian J. Anim. Sci., 22(2): 114-125.

Alewi, M., Melesse, A. and Teklegiorgis, Y. 2012. Crossbreeds effect on egg quality traits of local chickens and there F1 crosses with Rhode Island Red and Fayoumi chicken Breeds under farmers management conditions. J. Anim. Sci. Adv., 2(8): 697-705.

Elagib, H.A.A., Elamur, K.M., Ahmed, A.D.A. and Malik, H.E.E. 2012. Blood biochemical profile of males and females of three indigenous chicken ecotypes in Sudan. J. Vet. Adv., 2(12): 568-572.

Guttani, A., Pathak, A., Kumar, A., Mishra, V. and Bhatia, J.S. 2016. Influence of season and sex on hemato-biochemical trials in adult turkeys under arid tropical environment. Veterinary World., 9(5): 530-534.

Khan, W.A., Khan, A., Anjum, A.D. and Rehman, Z. 2002. Effect of induced heat stress on some biochemical values in broiler chicks. Int. J. Agric. Biol., 4(1): 2002.

Mishra, A.K. 1983. MVSC and AH Thesis on comparative studies on growth and hematology of Kadaknath and White leghorn chickens at different age groups. Jawaharlal Nehru Krishi Vishwa Vidhyalaya, Jabalpur, India.

Pandian, C., Thangapandiyan, M., Omprakash, A.V., Thyagarajan, D. and Babu, M. 2012. Effect of season on hematological profile and erythrocyte indices in white leghorn layers. Tamil J. Vet. Anim. Sci., 8: 389-392.

Panigraphy, K.K., Behera, K., Mohapatra, L.M., Acharya, A.P., Sethy, K., Panda, S and Gupta, S.K. 2017. Sex related differences in hemato-biochemical indices of adult Vanaraja chickens during summer and winter season. Vet. World, 10(2): 176-180. 
Polat, U., Yesilbag, D. and Eren, M. 2011. Serum biochemical profile of broiler chickens feed diets containing rosemary and rosemary volatile oil. J. Biol. Environ. Sci., 5(13).

Prameela Rani, M., Nissar Ahmad, N., Eswara Prasad, P. and Sri Latha, Ch. 2011. Hematological and biochemical change of stunting syndrome in broiler chicken. Vet. World., 3: 124-125.

Ripon Kumar Dutta, Saiful Islam, M. and Ashraful Kabir, M.D. 2013. Hematological and biochemical profiles of gallus indigenous, exotic and hybrid chicken breeds (Gallus Domesticus L.) from rajshahi Bangladesh. Bangladesh $J$. Zool., 41(2): 135-144.

Shanmathy, M., Tyagi, J.S., Gopi, M., Mohan, J. and Beulah, P. 2020. Effect of various factors on hematology and serum biochemistry values of Assel and Kadaknath chicken. Int. J. Curr. Microbial. App. Sci., 9(8): 1695-1703.
Singh, B., Hussain, K.Q. and Singh, D.S. 1998. Studies on certain blood parameters in guinea fowl. Indian J. Poult. Sci., 33: 202-206.

Mohanty, S., Mohapatra, S. and Acharya, G. 2020. Comparative hematology and biochemical parameters of indigenous and broiler chicken. Int. J. Scient. Technol. Res., 9(4): 972-979.

Bora, S., Gurram, S., Sagi, R., Tungani, R., Kandula, S. and Bobbili, R. 2017. Int. J. Livest. Res., 7(10): 231-237.

Tyagi, J.S., Singh, R.A., Sharma, R.K. and Sharma, P.K. 2007. Effect of saline drinking water simulated on pattern of underground water on hematology of broiler chicks. Indian J. Poult. Sci., 42: 37-42. 